\title{
Compreendendo as dimensões de cuidado em uma unidade de emergência hospitalar
}

\author{
Understanding care dimensions in an emergency hospital unit \\ Comprendiendo las dimensiones de cuidado en una unidad de emergencia hospitalar
}

\author{
Maria Aparecida Baggio', Giovana Dorneles Callegaro', AlacoQue Lorenzini Erdmann' \\ 'Universidade Federal de Santa Catarina. Departamento de Enfermagem, Programa de Pós-Graduação em Enfermagem, \\ Grupo de Estudos e Pesquisas em Aministração em Enfermagem. Florianópolis, SC
}

Submissão: 22/1 l/2008

Aprovação: 06/04/2009

\section{RESUMO}

Estudo Qualitativo Que objetivou compreender o significado das relações de cuidado de enfermagem em uma unidade de emergência na percepção do ser humano cuidado e proporcionar subsídios teóricos para pensar sobre as relações cuidativas estabelecidas no cotidiano do trabalho da enfermagem. Foram entrevistados 19 sujeitos em uma unidade de emergência hospitalar de Santa Catarina. Os dados foram submetidos à análise de conteúdo e interpretados pelo pensar complexo. As dimensões de cuidado, apresentadas em seis categorias, mobilizam e articulam as múltiplas competências humanas e técnicas dos/pelos seres cuidadores na compreensão do processo de cuidado em enfermagem, a partir da percepção dos Que são cuidados, e no repensar a própria prática e as condições múltiplas do ambiente como o espaço do cuidado.

Descritores: Cuidado; Enfermagem; Emergência.

\section{ABSTRACT}

The objective of this Qualitative study was to comprehend the meaning of the nursing care relationships in an emergency unit from the perception of the human receiving care and to provide theoretical subsidies in order to think about the care relationships established in day-to-day nursing work. Nineteen (19) subjects were interviewed in an emergency hospital unit in Santa Catarina, Brazil. The data was submitted to content analysis and interpreted according to complex thought. The care dimensions, presented in six categories, mobilize and articulate the multiple human competencies and techniques of/by caring beings in the comprehension of the nursing care process, from the perspective of those who receive care, including rethinking nursing practice itself and the multiple conditions of the environment as a space for care.

Descriptors: Care; Nursing; Emergency.

\section{RESUMEN}

Estudio cualitativo Que tuvo como objetivo entender el significado de la relación de cuidados de enfermería en una unidad de emergencia en la percepción de los seres humanos de cuidado y otorgar subvenciones para la reflexión teórica sobre las relaciones cuidativas en el trabajo diario de enfermería. 19 sujetos fueron entrevistados en una unidad de emergencias del hospital de Santa Catarina. Los datos fueron sometidos a un análisis de contenido y a la interpretación por el pensamiento complejo. Las dimensiones de lo cuidado, Que se presenta en seis categorías, movilizan y articulan las numerosas habilidades y técnicas de los/por los seres cuidadores en la comprensión del proceso de cuidado de enfermería en la percepción de aquellos que son cuidados, y repensar sus propias prácticas y múltiples condiciones ambientales como el ámbito del cuidado.

Descriptores: Cuidado; Enfermería; Emergencia. 


\section{INTRODUÇÃO}

Conforme o pensamento complexo ${ }^{(1,2)}$, os seres humanos são seres multidimensionais e complexos, Que contemplam ao mesmo tempo, os aspectos biológico, psíquico, social, afetivo e racional; são seres de subjetividade/intersubjetividade/objetividade, pensantes e conscientes de si, Que trazem em si sua irredutível individualidade/ coletividade, autonomia/dependência/interdependência, Que convivem culturalmente com regras, normas, proibições, estratégias, crenças, idéias, valores e mitos, mas Que também convivem com desregramentos, pertencentes a uma sociedade Que comporta as dimensões histórica, econômica, sociológica e religiosa.

Uma unidade de emergência é permeada de condições complexas inerentes ao próprio ambiente e aos seres humanos - Que cuidam e são cuidados - Que experienciam e vivenciam as também complexas relações humanas no processo de cuidar/cuidado, em um sistema organizacional hospitalar.

A partir da experiência profissional tanto na docência Quanto na assistência de enfermagem, observa-se Que alguns profissionais de enfermagem, no desempenhar de suas atividades em unidade de emergência, denotam a preocupação, como foco principal, nos aspectos biológicos do ser humano, sem considerar os demais aspectos do ser, na maioria das vezes. Dessa forma, fragmentam o cuidado, pois não consideram o ser humano em sua totalidade e complexidade.

No cuidado Que foca apenas órgãos, patologias, sinais e sintomas clínicos, a relação e interação entre os seres fica prejudicada. Considera-se que o cuidado deve ir além da visão biológica e biomédica, de modo a integrar as diversas unidades e multiplicidades dos seres. As ações do profissional de enfermagem em uma unidade de emergência precisam ser eficientes e eficazes, contudo, precisam valorizar também a subjetividade do ser humano.

Com base nas assertivas, Questionamos: Qual o significado das relações de cuidado em uma unidade de emergência na percepção do ser humano cuidado? E, dessa forma, propomos um estudo com objetivos de compreender o significado das relações de cuidado de enfermagem em uma unidade de emergência na percepção do ser humano cuidado e proporcionar subsídios teóricos para a enfermagem pensar sobre as relações cuidativas estabelecidas no cotidiano do seu trabalho.

O profissional de enfermagem ao atuar em unidade crítica de saúde deve demonstrar destreza, agilidade, habilidade, bem como, capacidade para estabelecer prioridades e intervir de forma consciente e segura no atendimento ao ser humano, sem esQuecer Que, mesmo na condição de emergência o cuidado é o elo de interação/integração/relação entre profissional e cliente.

Dessa forma, percebe-se a necessidade, segundo o pensamento complexo, de desenvolver o cuidado humano Que possibilite a visão individual e coletiva do ser humano e do ambiente Que este cohabita, aspirando-se o cuidado multidimensional, Que concebe e integra as múltiplas dimensões do ser humano ${ }^{(1,2)}$.

\section{METODOLOGIA}

O estudo utiliza o método Qualitativo e foi realizado em um hospital público estadual de Santa Catarina, em uma unidade de emergência.

O projeto de pesquisa foi aprovado pelo Comitê de Ética em
Pesquisa com Seres Humanos do Hospital Regional de São José, sob o número de protocolo 017/07, e foram respeitados os critérios éticos de pesquisas envolvendo seres humanos conforme a Resolução 196/96 ${ }^{(3)}$, do Conselho Nacional de Saúde, em todas as etapas da pesquisa.

A coleta de dados foi realizada através de entrevistas semiestruturadas, registradas por meio de gravador digital e observação não participante pelas pesQuisadoras. Os dados foram analisados Qualitativamente por meio da leitura e releitura das entrevistas de acordo com a análise de conteúdo, segundo Minayo ${ }^{(4)}$, e interpretados sob olhar do pensamento complexo ${ }^{(1,2)}$.

Neste estudo, o participante/cliente é entendido como ser cuidado e o ser de cuidado é o profissional Que atua, em sua prática profissional, na unidade estudada desenvolvendo ações e relações de cuidado. O participante/cliente é identificado pela letra P seguido de número ordinal correspondente a ordem da entrevista, exemplo (PI). A seguir pontuaremos alguns aspectos a acerca do cenário da emergência, ambiente do estudo, e, em seguida, as categorias analisadas como dimensões de cuidado.

\section{RESULTADOS E DISCUSSÃO}

\section{O cenário do cuidado do cliente/ser humano em uma unidade de emergência hospitalar}

Pôde-se observar Que a procura por atendimento pelos clientes, em sua grande maioria, é efetuada sem estar clinicamente em situação de gravidade. Poucos apresentam problemas de saúde efetivamente de caráter prioritário, ou seja, de urgência ou emergência, sendo Que muitos poderiam ser assistidos pela Rede Básica de Saúde.

Assim, corrobora-se com pesquisa feita no estado de São Paulo, num serviço de emergência, Que aponta ser, da totalidade dos clientes Que buscaram atendimento, apenas 3\% em situação de emergência, 9\% em situações de urgência e $88 \%$ não apresentavam situação crítica de saúde ${ }^{(5)}$. Contudo, a busca pela unidade de emergência "poderia ser o meio, aparentemente, mais fácil e rápido de obter a resolução de problemas de saúde"(6).

Independente do estado de saúde do cliente ser crítico ou não, as ações e relações de cuidado na unidade de emergência ocorrem naturalmente, num processo de mútua troca entre o profissional de enfermagem e o cliente, considerando-se as singularidades e também pluralidade dos seres, as experiências vividas e adeuiridas, isolada ou coletivamente. No cenário do cuidado, foram identificadas a partir da multiplicidade de relações e interações estabelecidas entre os seres humanos cuidadores e os seres cuidados, as seguintes dimensões de cuidado:

\section{Elo e empatia entre o ser cuidador e o ser cuidado}

Na relação de cuidado, conforme relatam os participantes, o profissional de enfermagem estabelece o elo entre o ser cuidador e o ser cuidado, e a partir de condutas imbuídas de zelo, atenção e respeito, fortalece a ligação entre os mesmos.

“a relação é ótima [...] muito bem acolhido” (PI).

"é o elo, o zelo pelas pessoas, cuidar é gostar, tratar bem [...]" (P3).

“...] tem que primeiro respeitar o outro, pra depois ser 
respeitado, ele vai ter mais amor e mais cuidado" (PI0).

\section{“|... elas tão sempre ali né, dando atenção...” (P7).}

A prática do cuidar desvela a importância da cordialidade entre as ações e relações humanas, as Quais se difundem simultaneamente, e revela de forma harmoniosa as divergências e convergências de cada ser, a unidualidade. Por sua vez, na teia de relações torna-se vital o contexto ser permeado por ações cuidativas, preocupação e respeito $^{(7)}$. Consequentemente, a preocupação e a responsabilidade com e pelo cuidado do outro advém da subjetividade do envolvimento e ligação afetiva estabelecida entre os seres.

A capacidade de empatia do profissional de enfermagem e a manifestação de atitudes permeadas de carinho, amor, delicadeza e atenção, atreladas à característica simpática deste ser, possibilitam ao cliente sentir-se cuidado e acolhido no ambiente hospitalar, mesmo Quando lotado. Assim, manifestam-se a dedicação e o compromisso com o cuidado Que fundamentam a prática profissional, como elucidam as falas a seguir:

\section{"[...] se colocar no lugar da pessoa que ta precisando de ajuda"} (PI3).

“... I a atenção, a delicadeza, sempre procurando o melhor pra gente" (P6).

“O cuidado... é bom [...] com amor e carinho" (P9).

“[...] são muito atenciosos, simpáticos e cuidam muito bem. [... geralmente aqui é lotado de gente pra eles atenderem, eles atendem muito bem mesmo" (P4).

\section{“[...] a dedicação, o compromisso, a atenção..." (P8).}

O profissional de enfermagem ao interagir com o ser cuidado demonstra e expressa emoções e sentimentos acerca do momento/ situação vivenciada, sendo a expressão do sentimento uma fonte de informação para conhecer o outro ser humano, Que possibilita a aproximação e a interação entre ser cuidado e o ser cuidador ${ }^{(8)}$.

\section{Ato de dar a medicação como importante responsabilidade do profissional da enfermagem}

O cliente, ciente da importância da medicação para o tratamento da enfermidade que o acomete, está atento aos horários em Que a recebe e para a continuidade deste cuidado, mesmo com e após a troca de plantão entre as equipes de enfermagem. Todavia, o ato de medicar, exercido pelo profissional de enfermagem, é conferido como de importante responsabilidade, Quando equiparado à prescrição deste pelo profissional da medicina. Este cuidado é enaltecido Quando atrelado a responsabilidade e ao conhecimento por parte do profissional acerca das condições clínicas do cliente inserido em uma unidade de emergência, o Que facilita e promove as ações do cuidado, como se observa nas seguintes falas:

\section{“[...] a medicação vem no horário certinho, é excelente” (PI I).}

“tem suas trocas (troca plantão da equipe enfermagem)... e o remédio na hora certa [...] tem uma Que é brincalhona, vem fazer a medicação bem contente" (PI2).

“O cuidado... enfermeiro é quase mais que um médico [...] médico não faz medicação, ele só prescreve, a responsabilidade de Quem é? do enfermeiro; se dá um remédio errado vai sobra pra Quem? é uma responsabilidade muito seria pro enfermeiro" (PI5).

“A equipe de enfermagem é excelente [...] saber o que o paciente tem; o que ele precisa [...] o medicamento que ele ta tomando [...] administrar o remédio, tão sempre atento" (PI3).

A prática do profissional de enfermagem Quando cerceada de atitudes Que denotam responsabilidade, preocupação e atenção proporciona segurança e excelência Quanto ao cuidado prestado, e ainda, constitui laços de confiança, como se observa nesta fala:

“|... eu confio nelas, tem Que confiar nas mãos daQuela enfermeira Que vem me trazer um remédio [...]" (PI0).

Reportando-se para a atuação da eQuipe de enfermagem, desvelase a fundamental importância de o profissional desempenhar suas ações e competências em confluência, através de conhecimento científico e destreza técnica, ou seja, a práxis, para transmitir confiabilidade durante a relação e a interação entre os seres envolvidos no processo de cuidado. Por outro lado, compete ao profissional de saúde compreender o ser cuidado/cliente considerando o todo e as partes, considerando o contexto com o Qual está engajado, a fim de atender as necessidades e expectativas deste ser.

\section{A importância da alimentação como uma necessidade do cliente}

O fato de a refeição do cliente, oferecida pelo hospital, ser constituída pelos mesmos alimentos Que compõe a refeição dos profissionais (médicos e demais profissionais) manifesta, na ótica do cliente, um tratamento de igualdade e exalta o sentimento de valorização e gratidão, como se lê nesta fala:

“tratam muito bem, eles dão almoço pra nós, geralmente o Que os médicos comem, os funcionários comem e a gente come a mesma coisa" (P5).

Em contrapartida, se constata a indignação de um dos participantes com o descaso da equipe de saúde com a sua alimentação, ou melhor, a sua falta, permaneceu várias horas sem ingestão alimentar, como afirma:

"deveriam se preocupar mais com as pessoas, dar comida, porque eu tô sem comida o dia inteiro, é ruim, daí a gente piora... desde ontem até hoje (mais de 15 horas) não comi nada [...] enfermagem poderia ajudar nisso [...] a pessoa não come, não melhora, o médico não passou nada, elas (enfermagem) não sabem... é complicado assim" (P17).

Denota-se através das falas manifestadas que a dimensão do cuidado com a alimentação/refeição é tão importante Quanto às 
demais dimensões de cuidado elucidadas, visto Que também é parte do cuidado, tanto para a cura e ou prevenção de patologias Quanto para o atendimento de necessidades humanas, sejam elas, biológicas, sociais, culturais, étnicas, religiosas, emocionais, psicológicas, etc. No entanto, percebe-se Que "... o momento da alimentação não é valorizado na assistência. Há necessidade de atendimento às individualidades, considerando Que, no processo patológico, a alimentação tem um significado emocional tão importante Quanto o terapêutico para o paciente, estando diretamente relacionada aos fatores socioculturais, étnicos, religiosos"(9).

Ainda, nas falas anteriores, é possível observar Que a comunicação e a correlação dos esforços pela equipe multiprofissional de saúde são deficitárias no Que tange ao atendimento da necessidade de comer do cliente. Identifica-se o descaso com a alimentação e nutrição, e porQue não dizer, descaso com o outro - ser humano, possuidor de necessidades, desejos, anseios, sentimentos...

O cuidado deve contemplar as necessidades do cliente, respeitando a singularidade/particularidade do ser, garantindo o suporte energético e nutritivo e fortalecendo o cuidado humano em suas múltiplas dimensões. Contudo, os seres cuidadores devem assegurar ao cliente o conhecimento das situações, condições e fatores, Quando for o caso, Que impossibilitam a ingestão alimentar, facilitando a compreensão por este sobre a importância da ausência do alimento para o próprio diagnóstico, tratamento e prevenção de complicações.

\section{A importância dos exames diagnósticos na atenção da equipe multiprofissional}

$\mathrm{Na}$ multidimensionalidade do cuidar percebe-se através dos depoimentos Que a seQüência do atendimento foi prontamente realizada pela equipe multiprofissional, sendo considerado de suma importância, principalmente os exames diagnósticos. Assim, referem:

\section{“[...] eu cheguei aqui, já logo entrei, já logo comecei a fazer os exames" (PI).}

"Cuidado é bom né, bater chapa raio $X$, exame de sangue eu fiz, agora eu fiz! Biópsia eu fiz duas vezes” (PI8).

"[...] a gente chegou cedo, correu tudo bem rápido, tanto o atendimento da medicação, Quanto os exames de laboratório..." (P7).

\section{“[... atendimento foi na hora, os exames, imediato..." (P I 5).}

Os depoimentos dos participantes remetem a satisfação com a agilidade e rapidez com Que foram atendidos, elucidando a atenção oferecida pelos profissionais de saúde para a realização dos exames diagnósticos complementares ao exame clínico, tais como, exame de raio $x$, de laboratório, biópsia, entre outros, Que foram realizados prontamente. A seQüência das ações diagnósticas realizadas denota destreza e ligeireza e implica conseQuentemente, na confirmação diagnóstica e início da terapêutica.

Em confluência ao pensamento explicitado anteriormente, para Que haja a seQüência correta destas ações cuidativas, compete aos profissionais de saúde, em especial a equipe de enfermagem, dispor de conhecimento profundo e especifico acerca das condições reais do cliente, visando obter solução diagnóstica e terapêutica, a fim de sanar as necessidades e expectativas do cliente ${ }^{(10)}$.

$\mathrm{Na}$ multidimensionalidade das ações, intervenções e relações do cuidar/cuidado, emerge por parte dos clientes, a importância em realizar exames diagnósticos, pois através destas ações os mesmos sentem-se cuidados e valorizados e, concomitante a isto, suscita a possibilidade da intervenção terapêutica.

\section{Diálogo como elo essencial de cuidado}

Essa dimensão de cuidado desvela Que a comunicação, o diálogo e a conversa, ou seja, a dialogicidade estabelecida entre o profissional da saúde e o cliente é o elo essencial de cuidado para a aproximação entre ser cuidado e o ser cuidador. No encontro dialógico os seres estabelecem, a partir da relação e da interação humana, momentos de troca, de interesse e preocupação com o outro e a maneira de expressão pode ser pela palavra falada ou mesmo comportamental e atitudinal, como se observa nos seguintes discursos:

\section{“A enfermagem sempre conversa [...]" (PI2).}

“.... a enfermagem conversa, perguntam o $Q$ gente sente, se precisa elas pedem socorro, ajuda, são muito atenciosas, são bem simpáticas" (PI4).

“[... os médicos, enfermeira todo ali, e eles perguntam, perguntaram se tá tonto, como é Que tá..." (PI2).

"Eu percebo por causa do atendimento deles, do jeito deles, do falar deles, do comportamento, é muito bom, fui muito bem atendida..." (PI).

A abertura para o diálogo favorece a promoção de relações de cuidado, pois permite a exposição de idéias e a expressão dos pensamentos, sentimentos, necessidades, anseios e desejos do outro $^{(1)}$, neste caso o profissional oportuniza e encoraja o cliente a dialogar e a expressar-se. Essa abertura torna possível a aproximação e compreensão da complexa teia de relações humanas de cuidado.

"Cuidar do outro é zelar para Que esta dialogação, esta ação de diálogo eu-tu, seja libertadora [...] construtora perene de paz e de amorização"(12). Nesta perspectiva, entende-se a relação de diálogo entre o ser cuidado e o ser cuidador, através da habilidade na Qual o profissional possui para entender e compreender a expressividade do outro, de forma amorosa e respeitosa ${ }^{(8)}$.

$\mathrm{Na}$ relação com o outro a expressão facial também pode manifestar o cuidado, pois "o rosto possui um olhar e uma irradiação da Qual ninguém pode subtrair-se. O rosto e o olhar lançam sempre uma pro-posta em busca de uma res-posta"(12).

Assim, sob a ótica do ser cuidado este fato foi clarificado nos depoimentos:

“|... Eles dão atenção, conversam, nunca estão de cara feia acho $\mathrm{Q}$ isso pode ajudar, eleva a auto-estima do paciente" (PI0).

“[...] o cuidado é a boa vontade do funcionário atender é uma relação boa, estão toda vida alegre [...]" (P9).

"I.. elas chegam brincando com a gente, se elas chegassem de 
cara feia eu ia passar mal pra caramba..." (PI0).

O modo dialógico também ocorre através da expressão da face, do olhar, dos gestos, da postura corporal... Configurando o cuidado não verbal, porém tão importante Quanto o verbal na relação de cuidado. Certamente a atitude, postura facial e corporal estreitam as interações e associações entre o ser cuidado e o ser cuidador, subsidiando e ao mesmo tempo Qualificando a prática da enfermagem.

As ações do ser cuidador para com o ser cuidado denotam o intuito de voltar-se ao outro, escutar o outro, oportunizar o diálogo, demonstrando preocupação e atenção com o outro, atitudes imprescindíveis para o cuidado humano, como aponta a fala:

"[... toda hora elas vem perguntar, dona Fulana, como ta? Dona Fulana esta melhor? Passou a dor? [...] eu acho muito importante" (PI0).

Dentre as dimensões do cuidar/cuidado, torna-se evidente Que a comunicação, seja ela verbal e ou não verbal, deve existir, a fim de facilitar, contribuir de forma positiva as ações/relações/interações entre o ser cuidado e o ser cuidador. Cada ser humano é conhecido e re-conhecido de forma única e singular, dotado de características específicas, Que constituem a essência do ser humano ${ }^{(13)}$. Portanto, implica visualizar estes indivíduos em sua totalidade, multiplicidade e complexidade, suprindo suas necessidades e expectativas ${ }^{(1)}$.

Ambiente em condições múltiplas como o espaço de cuidado

$\mathrm{Na}$ dimensão de cuidado do ambiente os clientes aludem sobre o aspecto limpeza e higiene no sentido de minimizar o acometimento de patologias e o desconforto. Na sua época, Nightingale desvelava preocupação com o meio ambiente o Qual o paciente estava inserido, como por exemplo, a organização, iluminação e temperatura do mesmo, pois para ela o meio externo poderia interferir de forma positiva ou negativa no processo do cuidar da equipe de enfermagem $^{(14)}$. As assertivas remetem a importância do cuidado com o ambiente em Que estão inseridos e, subjetivamente, a necessidade do fazê-lo, o que está deficitário - a higiene e limpeza, como elucidam as falas:

“O cuidado é a higiene pra não gerar outras doenças" (P 20).

“A limpeza né! O cuidado tem que ser a limpeza (do ambiente) tem Q ser" (P2I).

O cuidado humano em enfermagem deve propiciar um ambiente favorável para a restauração fisiológica e emocional do cliente ${ }^{(15)}$, sendo esta dimensão de cuidado, também de competência da enfermagem, visto Que deve assegurar como cuidado ao cliente o conforto, o aconchego, a calma e a tranqüilidade, bem como adęuadas condições de higiene e limpeza do ambiente.

$\mathrm{O}$ ambiente hospitalar remete ser tenso, sombrio, triste e, às vezes, desalentado, podendo ser causador de vulnerabilidade aos seres Que o habitam ${ }^{(16)}$. Dessa forma, os profissionais devem atentar para essa dimensão de cuidado visando proporcionar um ambiente/ meio/espaço saudável, traneüilo, confortável e livre de sujicidades, com vistas a aconchegar e igualmente proteger de outras e novas moléstias ocasionadas pela falta de cuidado com a limpeza do ambiente no meio hospitalar.

O ambiente é um espaço/meio pelo Qual convergem relações e interações Que possibilitam o aprimoramento tanto individual Quanto grupal dos seres humanos engajados no processo de cuidado. Neste cenário, onde transcorrem ações de saúde, a interação deve ser presente, embasada pelo respeito mútuo, como se observa no Questionamento do cliente a seguir:

"como é que ele vai me tratar bem se eu não respeito o espaço dele [...]?" (PI0).

Percebe-se que é primordial cada um respeitar o espaço do outro, compreendendo as pluralidades e particularidades de cada ser, pois o ser humano é ao mesmo tempo singular e múltiplo ${ }^{(1)}$. Este fato implica, mediante as relações e interações entre o ser cuidado e o ser cuidador que é vital existir um ambiente de lealdade e cordialidade entre ambos.

Além da precariedade apontada para o aspecto higiene, o depoimento a seguir assevera insatisfação com a falta de privacidade, de espaço e de silêncio, principalmente no período noturno:

“l... ser mais caprichoso, falta higiene, péssima higiene nos Quartos, mais privacidade, mais espaço, menos barulho de noite, todo mundo ta doente, uma falação, meu Deus, não é geral, mas é uma parte" (P22).

As necessidades dos seres cuidados fazem emergir a Qualificação dos serviços e atuação da equipe de enfermagem, tendo as ações/ interações/relações do cuidado como essência da profissão, visando atendê-los nas suas múltiplas dimensões ${ }^{(17)}$.

É imperativo Que o ser cuidador compreenda o contexto/ambiente em Que o ser cuidado e ele mesmo estão inseridos, globalmente. É preciso estar atendo aos detalhes Quanto à luminosidade, ruído, cor, odor, ventilação, temperatura, umidade... Ou seja, o profissional precisa exercitar a observação e reflexão crítica sobre o contexto, dada sua multiplicidade, para poder inferir positivamente no cuidado, estando para isso, também, atendo às queixas da clientela e dos demais membros Que convivem e se inter-relacionam no mesmo espaço temporal.

Reconhecer a importância do cuidado na relação entre ser cuidador e ser cuidado implica em valorizar a própria existência/ sobrevivência humana, cuja relação e interação traduz o real significado de dependência/independência entre os seres humanos, imbuídos de crenças, saberes, adQuiridos por experiências isoladas ou de forma coletiva, as Quais contribuem e definem a singularidade do ser humano.

\section{CONSIDERAÇÕES FINAIS}

Este estudo propiciou o encontro dos significados das relações de cuidado de enfermagem em uma unidade de emergência na percepção do ser humano cuidado, compreendidos em seis categorias, Que analisadas à luz da complexidade, proporcionam subsídios teóricos Que sustentam as práticas cotidianas desses profissionais. As relações estabelecidas envolvem múltiplas ações contempladas nas diferentes dimensões de cuidado descritas, Que mobilizam e articulam as competências humanas e técnicas dos e 
pelos seres cuidadores.

As categorias Que emergiram do processo de análise desvelam Que a enfermagem é o elo que articula e relaciona a rede de interações complexas de cuidado que compõem o sistema de cuidados no ambiente da emergência em suas ondições múltiplas como espaço do cuidado. As relações de cuidado são facilitadas através de atitudes e características exclusivamente humanas, por condições e ações técnicas como a medicação e a realização de exames diagnósticos e através dos momentos dialógicos promovidos por meio da comunicação, diálogo e conversa entre o ser cuidado e o ser cuidador, a empatia, Que viabilizam as trocas entre os seres de relação e de cuidado.

Retratam ainda, as categorias, Que os alimentos Que compõem a dieta dos clientes, em seu aspecto Qualitativo, são considerados por estes como de tratamento igualitário Quando equiparado a dieta dos profissionais, atribuído como um cuidado Que agrega valor e gratidão. Contudo, os profissionais devem estar atentos para a compreensão pelo cliente das impossibilidades de ingestão alimentar para fins de diagnóstico, tratamento e prevenção de complicações, se for o caso. E, se a condição não for esta, devem investigar o Que está imbricado com o não atendimento dessa dimensão de cuidado ao cliente, bem como a dimensão Que não contempla em sua totalidade a satisfação do cuidado com o ambiente Que o acolhe.

Ressalta-se a importância e valorização das relações humanas de cuidado, em suas múltiplas dimensões, a fim de promover ações e interações Que contemplem e respeitem o universo Que permeia o contexto onde o ser cuidador e o ser cuidado estão alocados, possibilitando a compreensão da complexa teia de relações entre os seres envolvidos no processo de cuidar/cuidado.

Sob a ótica das dimensões de cuidado, emergidas em categorias, confirma-se a importância da busca pelos seres cuidadores da compreensão sobre o processo de cuidado em enfermagem, a partir da percepção dos Que são cuidados, inclusive para repensar a própria prática.

\section{REFERÊNCIAS}

1. Morin E. Os sete saberes necessários à educação do futuro. São Paulo: Cortez; 2006.

2. Morin E. Introdução ao pensamento complexo. Porto Alegre: Sulina; 2006.

3. Ministério da Saúde (BR). Conselho Nacional de Saúde. Diretrizes e normas regulamentadoras da pesquisa envolvendo seres humanos: Resolução no.196/96. Brasília (DF); 1996. [citado em 17 jun 2000]. Disponível em: http:// www.ufrgs.br/ hcpa/gppg/res19696.htm.

4. Minayo MCS. O desafio do Conhecimento: Pesquisa Qualitativa em saúde. São Paulo: Hucitec-Abrasco; 2006.

5. Gatti MFZ Leão ER. O papel diferenciado do enfermeiro em serviço de emergência: a identificação de prioridades de atendimento. Rev Nursing 2004; 13(7): 24-9.

6. Marques GQL, Silva MAD. Demandas de usuários a um serviço de pronto atendimento e seu acolhimento ao sistema de saúde. Rev Latino-am Enfermagem 2007; 15(1): 13-9.

7. Boff L. Ethos Mundial: um consenso mínimo entre os humanos. Rio de Janeiro: Sextante; 2003.

8. Nascimento KC. As dimensões do cuidado em unidade crítica: emergindo o cuidado transpessoal e complexo [dissertação]. Florianópolis (SC): Universidade Federal de Santa Catarina.
Programa de Pós-Graduação em Enfermagem; 2005.

9. Campos SH, Boog MCF. Cuidado nutricional na visão de enfermeiras docentes. Rev Nutr 2006; 19(2): 145-55.

10. Volpato MP, Cruz DALM. Diagnósticos de enfermagem de pacientes internadas em unidade médico-cirúrgica. Acta Paul Enferm 2007; 20(2): 119-24.

11. Morin E. A cabeça bem-feita: repensar a reforma, reformar o pensamento. Rio de Janeiro: Bertrand Brasil, 2000.

12. Boff L. Saber cuidar: ética do humano - compaixão pela terra. Petrópolis: Vozes, 1999.

13. Santos CCV, Shiratori K. A influência da comunicação não verbal da enfermagem. Rev Bras Enferm 2005; 58(4): 434-7.

14. Carraro TE. Enfermagem e assistência: Resgatando Florence Nightingale. Goiânia: AB; 1997.

15. Waldow VR. Cuidado humano: o resgate necessário. Porto Alegre: Sagra Luzzatto; 1998.

16. Baggio MA. O (des)cuidado de si do profissional de enfermagem. [dissertação]. Concórdia (SC): Mestrado em Ciências da Saúde, Universidade do Contestado; 2004.

17. Erdmann AL. Os sistemas de cuidados da enfermagem. Pelotas: UFSC PEN; 1996. 